\title{
RESPIRATORY EPITHELIAL ADENOMATOID HAMARTOMA (REAH): A RARE ENTITY
}

L. Sushila Devi' ${ }^{1}$ Nisa Kaiho², Angelica Laiphrakpam³ ${ }^{3}$ D. C. Sharma ${ }^{4}$

\section{HOW TO CITE THIS ARTICLE:}

L. Sushila Devi, Nisa Kaiho, Angelica Laiphrakpam, D. C. Sharma. "Respiratory Epithelial Adenomatoid Hamartoma (REAH): A Rare Entity". Journal of Evolution of Medical and Dental Sciences 2015; Vol. 4, Issue 32, April 20; Page: 5577-5580, DOI: 10.14260/jemds/2015/815

\begin{abstract}
Respiratory epithelial adenomatoid hamartoma (REAH) is a rare benign lesion of the upper aerodigestive tract seen mainly in adult males. The lesion usually occurs in the nasal cavity though other locations have also been described. Recognition and awareness of this lesion is necessary as it may be confused with more aggressive lesions which require a significantly different treatment approach. A complete surgical resection is curative for REAH. We report a case of REAH in an adult male presenting with a mass in the nasal cavity. This case is reported because of its rarity and the potential risk of misdiagnosis.
\end{abstract}

KEYWORDS: Inverted papilloma, nasal mass, respiratory epithelial adenomatoid hamartoma, sinonasal adenocarcinoma.

INTRODUCTION: 'Hamartoma' is a rare, non-neoplastic malformation of tissue producing a mass of disorganized but mature specialized cells or tissues indigenous to the particular site. They are common in the lung, kidney, liver, and spleen and intestine but are extremely rare in the upper aero digestive tract. ${ }^{1}$ Unlike neoplasms, these lesions do not grow continuously, resulting in a self-limiting proliferation. ${ }^{1,2,3}$

CASE HISTORY: A sixty year old male presented with a right nasal mass. He gave a history of longstanding nasal obstruction, hyposmia and recurrent rhinorrhoea. Physical examination and computerized tomography (C.T.) revealed a right nasal mass in the lateral wall of the nasal cavity. Surgical excision of the mass was done and the tissue was sent for histopathological examination with a clinical diagnosis of inverted papilloma. The patient was asymptomatic with no recurrence of the lesion at 12 months follow-up.

Pathological Findings: Grossly, there were multiple yellowish-white, polypoidal tissue pieces, altogether measuring 2.5x2x1.5 cms. Microscopical examination using hematoxylin and eosin (H\&E) stain showed a ciliated respiratory surface epithelium having bland nuclear chromatin with numerous glandular spaces lined by the same type of epithelium underneath it. The glands are situated in a fibro-collagenous edematous stroma containing numerous chronic inflammatory cells (Figure1). The glands are of different sizes, many of them containing mucinous/amorphous debris and are surrounded by thick basement membranes (Figure2). Based on these findings, a diagnosis of respiratory epithelial adenomatoid hamartoma was made.

DISCUSSION: Respiratory epithelial adenomatoid hamartoma (REAH) is an uncommon benign lesion. To our knowledge, approximately seventy cases have been reported in literature. It has been hypothesised that it arises from the schneiderian epithelium like the normal seromucous glands of the nasopharynx and paranasal sinuses. 
The mechanisms responsible for the development of REAH are still unknown. It is now thought that inflammation may be a contributory factor in its development.2,4 which may be supported by its frequent association with nasal polyps, rhinosinusitis and sinus surgery. ${ }^{4}$ Association with nasal polyposis, tobacco use and asthma have also been described. ${ }^{2,3}$

The present case is a chronic smoker and also had chronic sinusitis. Xing Hua et al studied the correlation between REAH and Epstein Barr virus (EBV) and concluded that EBV had nothing to do with REAH. 5 They also observed that the epithelial components were negative for p53 and a labeling index of $<1 \%$ for Ki-67 stains in the basal layer supporting its benign nature. Ozolek and Hunt observed appreciable allelic loss within REAH at much higher rates than expected for a nonneoplastic entity. ${ }^{6}$ They suggest the possibility of REAH to be a benign tumor rather than a hamartoma.

REAH commonly affects adult men in the third to ninth decades of life with the median age in the sixth decade. ${ }^{7}$ Wenig and Heffner described the median age to be fifty eight years with a male to female ratio of roughly 7:1.2 It occurs most commonly as a unilateral mass in the nasal cavity, 1,2 the most common site being nasal septum, particularly the posterior part. Less commonly, it may be present as a bilateral lesion. ${ }^{8}$ In the nasal cavity, the lesions are seen arising along the lateral wall, middle meatus or inferior turbinate. ${ }^{7}$ Other rarely affected sites are paranasal sinuses and nasopharynx..$^{2,6}$

Lesions tend to be polypoid, fleshy to firm in consistency and yellowish white in colour. The largest lesion reported till date is $5 \mathrm{~cm}$ in its greatest dimension. ${ }^{9}$ Microscopically, it is characterized by glandular proliferations of different sizes lined by ciliated respiratory epithelium with lumina often filled with mucinous/amorphous debris. Some of the glands may have direct continuity with the surface epithelium. The glands are widely spaced and surrounded by thick eosinophilic basement membranes. ${ }^{8}$ other histological features described in REAH include stromal edema with inflammatory cell infiltrates, polypoidal growth, seromucinous gland proliferations, vascular and fibroblastic proliferations. REAH with chondro-osseous differentiation have also been described.10 Symptoms at presentation vary and include nasal congestion and obstuction, headache, epistaxis and hyposmia which are similar to chronic rhinosinusitis.

Diagnostic misinterpretation is a serious issue regarding REAH. It may be confused with more aggressive lesions such as inverted papilloma (IP) and sinonasal adenocarcinoma (SNAC) which require aggressive surgical resection. In the present case, the mass was identified in the right lateral nasal wall, a site where IP are more common, leading to a clinical diagnosis of IP. It is characterized by the presence of hyperplastic islands of squamous epithelium with intraepithelial presence of neutrophils. The basement membranes around the epithelial islands are thin and delicate. In addition to its locally aggressive behaviour, it also has potential for malignant transformation and recurrence may also occur.

Differentiation from SNAC can be made by the presence of intervening stroma between the glands, individual glands surrounded by thick eosinophilic basement membranes and the presence of ciliated epithelium lining expanding lumens. Furthermore, REAH does not show cellular pleomorphism.

Endoscopy, CT or magnetic resonance imaging (MRI) may not be helpful in differentiating REAH from other sinonasal lesions. ${ }^{3}$ Diagnosis of REAH is made by histopatholgical examination. 


\section{CASE REPORT}

CONCLUSION: REAH is an uncommon, recently described entity characterised by respiratory epithelial adenomatoid proliferations which originate from the surface respiratory epithelium. Further molecular studies will be essential for better understanding of the pathogenesis of REAH. Despite its rarity, REAH should be included in the differential diagnoses of nasal exophytic lesions. Clinicians and pathologists must be aware of REAH in order to avoid over diagnosis and unnecessary aggressive surgical interventions.

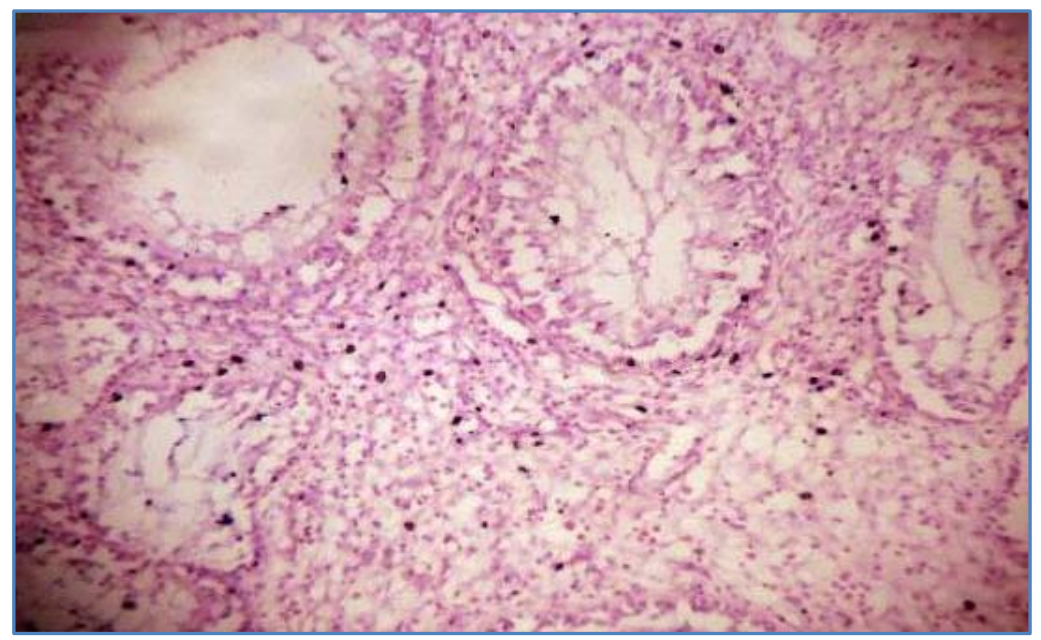

\section{Fig. 1: H \& E X 40}

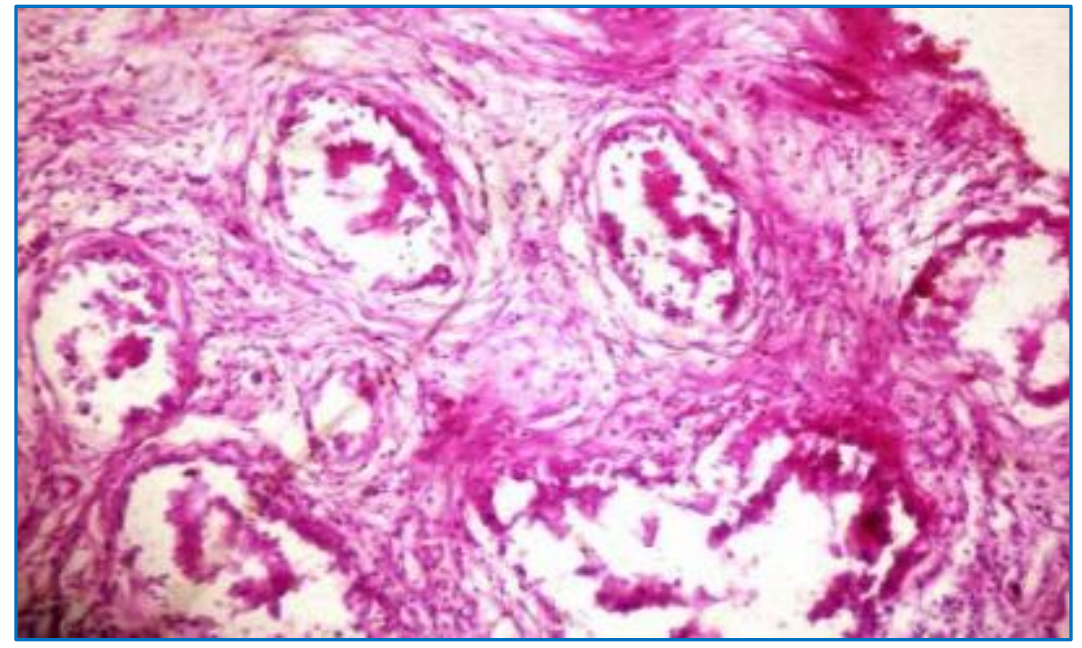

Fig. 2: PAS X 10

\section{REFERENCES:}

1. Endo R, Matsuda H, Takahashi M, Hara M, Inaba H, Tsukuda M. Respiratory epithelial adenomatoid hamartoma in the nasal cavity. Acta Otolaryngol 2002; 122:398-400.

2. Wenig BM, Heffner DK. Respiratory epithelial adenomatoid hamartomas of the sinonasal tract and nasopharynx: a clinicopathologic study of 31 cases. Ann Otol Rhinol Laryngol 1995; 104:639-45. 
3. Delbrouck C, Fernandez Aguilar S et al. Respiratory epithelial adenomatoid hamartoma associated with nasal polyposes. Am J Otolaryngol 2004; 25:282-4. doi:10.1016/J.amjoto.2004.02.005.

4. Seol JG, Livolsi VA, O'Malley Jr BW, Chen JY, Loevner LA. Respiratory epithelial adenomatoid hamartoma of the bilateral olfactory recesses: a neoplastic mimic? AJNR 2010; 31:277-9.

5. Hua X, Huang X, Liao Z, Xian Q, Yu L. Clinicopathological and EBV analysis of respiratory epithelial adenomatoid hamartoma. Diagn Pathol 2014; 9:70. Doi: 10.1186/1746-1596-9-70.

6. Ozolek JA, Hunt JL. Tumor suppressor gene alterations in respiratory epithelial adenomatoid hamartoma (REAH): comparison to sinonasal adenocarcinoma and inflamed sinonasal mucosa. Am J Surg Pathol. 2006; 30:1576-80.

7. Carlo RD, Rinaldi R, Ottaviano G, Pastore A. Respiratory epithelial adenomatoid hamartoma of the maxillary sinus: case report. Acta Otorhinolaryngol Ital 2006; 26(4):225-7.

8. Barnes L. Schneiderian papillomas and nonsalivary glandular neoplasms of the head and neck. Mod Pathol 2002; 15(3):279-97.

9. Mills SE, Gaffey MJ, Frierson HF. Miscellaneous tumor like lesions. In: Atlas of tumor pathology: tumors of the upper aerodigestive tract and ear $3^{\text {rd }}$ series. Washington DC: Armed Forces Institute of Pathology; 2000.p.357-9.

10. Roffman E, Baredes S, Mirani N. Respiratory epithelial adenomatoid hamartomas and chondroosseous respiratory epithelial adenomatoid hamartomas of the sinonasal tract: a case series and literature review. Am J Rhinol. 2006; 20:596-90.

\section{AUTHORS:}

1. L. Sushila Devi

2. Nisa Kaiho

3. Angelica Laiphrakpam

4. D. C. Sharma

\section{PARTICULARS OF CONTRIBUTORS:}

1. Assistant Professor, Department of Pathology, Jawaharlal Nehru Institute of Medical Sciences, Imphal, Manipur.

2. Senior Resident, Department of Pathology, Jawaharlal Nehru Institute of Medical Sciences, Imphal, Manipur.

3. Medical Officer, Manipur Health Service, (MHS), Imphal, Manipur.

FINANCIAL OR OTHER COMPETING INTERESTS: None
4. Professor, Department of Pathology, Jawaharlal Nehru Institute of Medical Sciences, Imphal, Manipur.

\section{NAME ADDRESS EMAIL ID OF THE CORRESPONDING AUTHOR:}

Dr. Nisa Kaiho, Department of Pathology, Jawaharlal Nehru Institute of Medical Sciences, Imphal, Manipur

E-mail: nkaiho@rocketmail.com

Date of Submission: 25/03/2015. Date of Peer Review: 26/03/2015. Date of Acceptance: 08/04/2015. Date of Publishing: 20/04/2015. 